\title{
UMA EXPERIÊNCIA DE FORMAÇÃO DE PROFESSORES PARA O USO DAS FERRAMENTAS DIGITAIS E CRIAÇÃO DE REDES DE APRENDÊNCIA
}

\author{
Selma Bessa Sales ${ }^{1}$, Alba Liarth da Cruz ${ }^{2}$ \\ ${ }^{1}$ Centro de Referência do Professor (CRP), - Núcleo de Tecnologia Educacional - \\ (NTE) Secretaria Municipal de Educação de Fortaleza (SME). \\ Rua Conde D'Eu, 560 - Centro, CEP: 60.055-070 \\ 2 Universidade Estadual do Ceará (UECE) - Centro de Humanidades (CH) \\ Av. Luciano Carneiro, 345 - Aeroporto - Fortaleza Cep: 60.410-000 - Fortaleza - CE \\ selmabessa0808@gmail.com, albaliarth@gmail.com
}

\begin{abstract}
This paper presents a formative experience with teachers from the Rede Municipal de Ensino at Centro de Referência do Professor. On this occasion, the teacher developed their knowledge and pedagogical practices in innovative actions, based on the use of digital tools to design and dynamics of learning networks. Through action research, it was found that this teacher, by appropriating some Web 2.0 tools such as online editing (Blog and Wiki), online communication (Skype), access to videos (YouTube), collaborative writing (Google Docs), learning environments (Socrates, teacher's Portal and Edmodo) social networking (Twitter and Facebook), understood as auxiliary resources in teaching, acquired innovative teaching positions with unusual ways to think, create, learn and share knowledge.
\end{abstract}

Resumo: Este artigo apresenta uma experiência de formação com os professores da Rede Municipal de Ensino, no Centro de Referência do Professor. Na oportunidade, o professor desenvolveu seus saberes e práticas pedagógicas em ações inovadoras, partindo do uso das ferramentas digitais para elaboração e dinamização das redes de aprendência. Por meio da pesquisa-ação, constatou-se que o professor-cursista, ao se apropriar de algumas ferramentas da Web 2.0, como edição on-line (Blog e Wiki), comunicação on line (Skype), de acesso a vídeos (You Tube), escrita colaborativa (Google Docs), ambientes de aprendizagem (Sócrates, Portal do Professor e Edmodo), redes sociais (Twitter e Facebook), compreendidas como recursos auxiliares no ensino, adquiriu posturas pedagógicas inovadoras, com inusitadas formas de pensar, criar, aprender e compartilhar conhecimento.

\section{Introdução}

No cenário educacional de Fortaleza/Ce os professores podem contar com um centro de formação denominado Centro de Referência do Professor - CRP, que procura cumprir sua função socioprofissional na medida em que oportuniza a formação continuada como suporte ao processo de ensino-aprendizagem. Suas principais ações são: formação dos professores para uso das $\operatorname{TICS}^{1}$ na educação, acompanhamento pedagógico do trabalho dos $\mathrm{LIE}^{2}$ e apoio a projetos de uso das tecnologias nas escolas.

Este relato descreve uma experiência de formação no referido Centro com os participantes do Curso Redes Sociais: espaço de ensino e aprendizagem que teve como objetivo esclarecer e dar ideias práticas ao professor de como elaborar e dinamizar as redes de aprendência, ao longo do processo de ensino-aprendizagem através da apropriação e integração de ferramentas digitais. O referido curso foi planejado para que os participantes vivenciassem o uso de redes sociais e ambientes de aprendizagem e comunicação online como promotores de interatividade e colaboração.

\footnotetext{
${ }^{1}$ Tecnologias da Informação e Comunicação

${ }^{2}$ Laboratório de Informática Educativa
} 
Em geral, esses espaços virtuais não são utilizados em todas suas possibilidades, muito menos nos aspectos pedagógicos, fazendo-se necessário, portanto, que a escola e os educadores compreendam que é possível transformar a situação das redes sociais em espaços pedagógicos que se abrem através das relações surgidas entre pessoas e seus contatos. Alguns estudos (Barcelos, Passerino, Behar, 2011, Da Silva, 2010, Balbino, Anacleto, 2011) sobre o uso das redes sociais, apresentam essa experiência como uma ferramenta potencial que pode favorecer o aprendizado crítico e participativo ao transformar os espaço e tempo em espaços pedagógicos.

A partir desse contexto, a pesquisa estruturou-se sob o foco da análise de que a construção do conhecimento é elaborada através de novos processos metodológicos de aprendizagem. Ao pensar a formação dos professores, foram oferecidos subsídios teóricos, metodológicos e práticos para a compreensão do potencial pedagógico dos recursos tecnológicos no ensino e na aprendizagem. Nesse intuito também foi pontuada a vivência da inserção, apropriação e integração das ferramentas digitais nas atividades sugeridas, no planejamento de estratégias de ensino e aprendizagem, nas situações de aprendizagem de forma criativa e no trabalho colaborativo. Isso resultou efetivamente na construção de conhecimentos e habilidades para a elaboração das redes de aprendência, propiciando ao professor uma reformulação no aprender e ensinar.

Nesse sentido, encontram-se nas ferramentas da Web 2.0 possibilidades para a construção do conhecimento dentro da proposta do curso. Na Wikipédia ${ }^{3}$, uma definição sobre ferramentas Web 2.0 descreve-a como uma "segunda geração de comunidades e serviços através de uma plataforma virtual envolvendo wikis, aplicativos, redes sociais e tecnologias da informação aproveitando a inteligência coletiva".

Essas ferramentas abrem um leque de possibilidades para o desenvolvimento do processo ensino-aprendizagem devido a facilidade de uso e a velocidade na divulgação das informações. Informações que são transformadas em conteúdos significativos e adequam-se à prática educativa a ser desenvolvida na formação.

\section{O professor está na rede e agora?}

$\mathrm{O}$ instigante e dinâmico processo pelo qual a sociedade vem passando diante das inovações tecnológicas requer do professor novos conhecimentos e habilidades pois durante muito tempo o papel dele resumia-se a dar aula, transmitir informações, selecionar o conteúdo, assumindo assim, uma modelo autoritário de "dono da verdade".

Com o avanço das tecnologias, a Web que antes era somente "lida" pelo professor, possibilitou que o mesmo mudasse de papel, tornando-o produtor de conhecimento de forma democrática, livre e gratuita através da rede. Isso aconteceu graças ao surgimento da Web 2.0. Essas ferramentas provocaram na educação um maior envolvimento entre as áreas tecnológica e educacional promovendo a qualificação dos envolvidos exigindo novos padrões de desenvolvimento. Nesse momento é dado mais estímulo à criatividade do cursista e valoriza-se mais a interação e troca de informação entre professor e aluno, tornando o ensinante ao mesmo tempo aprendente.

\footnotetext{
A web é para ligar pessoas, a web 2.0 é para ligar pessoas, pessoas compartilhando, trocando, colaborando... Nós precisamos repensar algumas coisas, precisamos repensar os direitos autorais, repensar a autoria, e pensar a identidade, repensar a ética, repensar a estética, repensar a retórica, repensar o ato de governar, repensar a privacidade, repensar o comércio, repensar o amor, repensar a família e repensar nós mesmos (WESCH, 2007).
}

\footnotetext{
${ }^{3}$ Disponível em http://pt.wikipedia.org/wiki/Web_2.0 acesso 10/04/2011
} 
A comunicação e interação que essas ferramentas proporcionam aumentam as chances do estabelecimento de criação de laços sociais entre as pessoas via comunicação mediada pelo computador (Recuero, 2004), o que nos traz questionamentos quanto à formação dos profissionais de educação em relação aos conhecimentos de informática e a sua utilização em sala de aula.

É nessa perspectiva que algumas questões se apresentam como desafios e motivam inúmeras investigações. Buzato (2006) lista algumas: O que se espera do uso dessas novas tecnologias na educação? O que se espera do professor? Como formar professores em vista dessas necessidades? Uma pergunta útil e que nos fornece um ponto comum relaciona-se à questão de quais seriam as ferramentas digitais mais adaptadas às necessidades curriculares? Quais abordagens metodológicas submetem esses recursos fundamentais à educação, à promoção e à apropriação dessas tecnologias pelo professor de forma autônoma e significativa?

Os recursos da Web 2.0 aqui descritos e utilizados no curso, que tiveram destaque no gerenciamento (Tori, 2010) e no impacto na forma de ensinar e aprender foram: ambientes colaborativos online (Facebook, Twitter, Blog, Socrates, Edmodo, Portal do Professor, YouTube); aplicativos do Google Docs e ambiente de comunicação (Skype). As atividades didático-pedagógicas do curso foram desenvolvidas dentro desses espaços promovendo o espírito de colaboração e de autonomia aos professorescursistas.

Entretanto, o uso das tecnologias digitais não será suficiente sem a devida intervenção das novas formas de ser, estar e relacionar-se do professor/aluno com o mundo. É nessa perspectiva que se verifica a importância do uso da Web 2.0 como meio adequado para a aprendizagem em rede. E por meio dessas ferramentas investigaremos se a apropriação e a articulação das mesmas favorecem a elaboração das redes de aprendência.

Assim, para a referida formação, buscou-se investir na preparação do professor sugerindo-lhe compreender as características constitutivas das tecnologias que tenham sido apresentadas para integrar adequadamente o conhecimento técnico às propostas pedagógicas inovadoras. Considera-se, então, que não basta introduzir as tecnologias ao cotidiano do professor, foi fundamental pensar como elas podem ser usadas efetivamente no processo de ensino-aprendizagem.

\section{Como pensar uma educação sob a perspectiva de redes?}

Diante de situações inovadoras que ora se apresentavam para atender estas novas possibilidades foi proposto ao professor experienciar os desafios de um novo aprender. Nessa perspectiva de investigar sobre o aprender a aprender por meio da criação de redes de aprendência se enquadra o presente estudo, uma vez que se pretende verificar se, através do aprender fazendo, o professor inova sua prática docente associando os conteúdos e as competências de uma atividade pedagógica ao utilizar as ferramentas digitais.

Almeida e Moran (2005) sugerem que os recursos digitais sejam utilizados para contribuir no processo de construção do conhecimento e não apenas como recurso auxiliar no ensino. Ideia que nos ajudou a pensar as atividades práticas nas redes sociais e em ambientes de aprendizagem online, com ênfase na vivência de uso das ferramentas digitais já citadas anteriormente.

Nesse contexto, surge com enfoque especial a busca pela formação de um profissional prático, reflexivo, investigador e crítico, visando à promoção constante de seu desenvolvimento profissional e à construção de novos saberes. Perrenoud (2000) discorre sobre o desenvolvimento das competências fundamentadas em uma cultura 
tecnológica e sugere que, para ensinar o uso de novas tecnologias faz-se necessário a criação de "cultura tecnológica, incluindo o uso da informática e das demais tecnologias de comunicação e informação, explorando suas potencialidades didáticas".

Diante da experiência oriunda da incorporação do conjunto de valores e saberes bem aproveitados, do conhecimento das técnicas para uso das ferramentas tecnológicas e da compreensão das possibilidades que esses recursos podem oferecer para a construção de conhecimento, o professor-cursista foi desafiado a "assumir uma postura de aprendiz ativo, crítico e criativo, constante investigador sobre seu nível de desenvolvimento cognitivo, social e afetivo" (Almeida, 2005), em face de suas expectativas e necessidades para o uso dos recursos da Web 2.0 na criação das redes de aprendência.

Nesse momento, os saberes profissionais foram valorizados e foi constatado, que, muitos já estavam fazendo uso amplo das redes sociais de forma individual, mas não haviam ainda tido uma formação que lhes fornecessem orientações para uso, por exemplo, do Twitter e do Facebook de forma extensiva, articulada e com responsabilidade para aproveitamento pedagógico. Destacam-se aqui as palavras de Kenski (2009), nos chamando atenção para o fato de que: o importante não é apenas usar o facebook ou o twitter, mas sim criar sua própria rede, cuidando para que seja dado um novo sentido e uma nova forma para inseri-los no cotidiano da sala de aula.

Como produto final da formação continuada foi proposta a criação de redes de aprendência para difusão da prática docente de cada participante do curso. Nesse sentido foram pensadas estratégias inovadoras para motivá-los a constituir uma verdadeira rede. Para melhor compreensão sobre aprendência e suas implicações para a formação de professores, tomou-se como base norteadora o que sugere o Fórum "Uso de redes sociais na escola: criando Redes de Aprendência. Web 2.0 \& Transdisciplinaridade", onde aprendência ${ }^{4}$ é um neologismo que indica um processo que ocorre durante toda a vida diante da relação entre o educante /aprendente, visto que somos capazes de aprender ao longo de toda a vida.

Para Fabre (2004 apud Fichmann, 2005 p. 12), "o papel dos educadores é o de lembrar ao aprendente (aluno) que aprender é por essência, a recusa ao fechamento", o que nos leva ao entendimento de que para ocorrer aprendência faz-se necessário que seja estabelecida uma troca, onde cada um participa emitindo e recebendo, constituindose uma relação viva entre educante/aprendente. Alunos e professores são aprendentes e educantes de acordo com a visão transdisciplinar ${ }^{5}$ a partir da formação que emerge da relação com si mesmo, da relação com o outro e da relação com o ambiente. As atividades desenvolvidas nessa formação foram, portanto, concebidas de acordo com essas ideias.

A ênfase dada para a formação foi o desenvolvimento de estratégias, no sentido de que o professor, com rapidez e com eficiência, fosse capaz de inovar sua maneira de aprender e ensinar, para gerar mudanças no processo educacional através da criação de redes de interação e conhecimento (Fichmann, 2005). O grande desafio, entretanto, constituiu-se em planejar uma rede de aprendência para aplicar aos alunos partindo de um roteiro simples que constava de: objetivos, fundamentação transdisciplinar, públicoalvo, definição do ambiente virtual a ser utilizadas (rede social), atividades a serem desenvolvidas: cronograma, estratégias de mediação, acompanhamento e avaliação.

\footnotetext{
${ }^{4}$ Sobre o processo de aprendência, ler http://www.cetrans.com.br/textos/publicacoes/nascemos-paraaprender.pdf acesso em 15/10/2011

${ }^{5}$ Como diria FICHMANN (2005) a Transdisciplinaridade fundamenta-se também na formação tripolar AUTOFORMAÇÃO, HETEROFORMAÇÃO e ECOFORMAÇÃO.
} 
O professor-cursista ao criar sua rede de aprendência uniu a teoria e a prática na vivência de momentos, nos quais, ele, aprendente, envolve-se e sente-se motivado diante dos desafios para criar atividades interessantes que proponham interatividade e que primem pela qualidade e não pela quantidade de conteúdo. Nessa interação, o ponto alto é aquele momento, que apresenta como pano de fundo a ação imediata do educador, através de diálogos, da efetiva formação de competências e da formação humana.

Para que se responda a essa expectativa, sugere-se ao professor que na elaboração do roteiro seja contemplada em primeiro lugar, a atividade pedagógica, visto que não é apenas a inserção da tecnologia que garante o aprendizado.

\section{Transformando saberes em práticas pedagógicas}

O curso ocorreu no período de abril a julho de 2012 envolvendo duas turmas totalizando vinte e seis professores participantes que sinalizaram para a necessidade de investir ainda mais nesse modelo de formação a fim de enfatizar o processo de formação continuada.

Os professores envolvidos no curso acreditaram no potencial de uso das ferramentas Web 2.0 para a comunicação, para a colaboração e para o compartilhamento de informações. Dessa forma a abordagem dos conteúdos do curso foi feita no contexto da transdisciplinaridade, proposta essa inserida nos ambientes que incentivavam o autoposicionamento, o questionamento e a avaliação dos participantes em relação aos conteúdos abordados. Portanto, com esse intuito o foco na aplicabilidade em sala de aula de modo a gerar mudanças na qualidade da prática docente foi tomado como ponto de partida para a utilização e integração das ferramentas digitais apresentadas.

Primeiramente foi necessário explicitar o uso de algumas ferramentas da Web 2.0 (na prática) para contribuir com a realidade prática no processo de ensinoaprendizagem, para que em seguida e através do roteiro para criação da rede de aprendência, verificar se os ambientes apresentavam os recursos necessários para tal utilização.

Ao longo da formação ficou evidente que, muitos participantes já faziam uso das ferramentas das redes sociais, como blog, twitter, facebook sem o foco no pedagógico. Pontes e Castro-Filho (2011) nos remetem à ideia de que é possível aumentar a participação do usuário na internet fazendo com que ele abandone a posição de receptor passivo e assuma a posição de produtor de conteúdo.

Diante disso, a proposta de formação foi elaborada a partir da concepção de ensino-aprendizagem construtivista, onde cada participante foi sujeito de sua própria aprendizagem, destacando o "aprender a fazer fazendo", estimulado pela aprendizagem cooperativa e colaborativa. E baseado numa metodologia teórico-prática, o curso foi organizado a partir de momentos presenciais e a distancia, tendo a relevância do conteúdo associado à realidade vivida pelos professores cursistas.

O curso foi previsto com sessenta horas/aula sendo vinte e quatro dessas distribuídas em oito encontros presenciais. E trinta e seis horas à distância para o desenvolvimento das atividades práticas. Assim posto, todas as atividades propostas foram realizadas com facilidade, envolvendo as ferramentas digitais nas redes sociais e nos ambientes de aprendizagem online onde a clareza do objetivo foi inserida nessa experiência educativa.

À medida que o curso ia acontecendo tornava-se cada vez mais necessário um fazer educativo que oferecesse cenários diversos e alternativos, sintonizados com as 
novas maneiras de pensar exigidas pelo ciberespaço ${ }^{6}$, onde a tecnologia é incorporada de forma adequada ao contexto das ações educativas. Assim foi à estratégia adotada no curso para transformar o obrigatório em prazeroso.

De acordo com Balbino e Anacleto (2011), os ambientes das redes sociais configuram-se como um meio potencial para a extensão de práticas educativas bem como criam um ambiente favorável para novas aprendizagens. $\mathrm{O}$ ponto inicial para $\mathrm{o}$ levantamento prévio dos recursos digitais possíveis para a elaboração e a dinamização de uma rede de aprendência consistiu na verificação da usabilidade e da aplicabilidade de ferramentas síncronas e assíncronas que permitissem implementar práticas de autoria coletiva e de colaboração online.

No âmbito da preparação de professores, detalham-se, a seguir, algumas ações pedagógicas utilizadas no processo de aprender e ensinar que contribuíram significativamente para o enriquecimento do curso.

Na primeira semana foram feitos: a ambientação dos participantes no sistema on line para criação de projetos e comunidades-Sócrates ${ }^{7}$, disponibilizando o referencial teórico da formação; dois fóruns; na ferramenta "Comentários", espaço para registro das contribuições, a elaboração de um "Wiki" ilustra este momento de criação de forma colaborativa oriundo da discussão: "Possibilidades de uso das Redes Sociais como espaço pedagógico". Foram escolhidas as ferramentas de "Apresentação" e "Processamento de Textos" disponibilizados no Google Docs", para o compartilhamento do planejamento das aulas diárias. Essas ferramentas despertam muito interesse por que permitem o compartilhamento dos conteúdos do curso fomentando uma maior autonomia do aluno ao estudar de forma individual ou colaborativa.

Foi criada uma conta na rede social Facebook ${ }^{9}$, com o objetivo de dinamizar a troca de informações e permitir aos integrantes do curso a tomada de decisão em tempo real. Inaugurando assim um importante espaço de autoria coletiva, possibilitando também a criação de grupos nas diversas áreas do conhecimento (Grupo de Ciências, PAIC, Matemática,...), e a inclusão de fotos, vídeos e textos. Destaca-se nessa prática a criação de um repositório com o objetivo principal de reunir elementos inspirados em ferramentas de colaboração e comunicação (Chamada com vídeo, Nota, Grupos, Mensagem), que podem servir para ilustrar ou contar as ações pedagógicas realizadas no decorrer da formação.

Por conseguinte, as aulas tornam-se mais dinâmicas com os alunos interessados e participativos. Outro ponto alto do curso foi a participação dos cursistas no Portal do Professor - Fórum Uso de redes sociais na escola: criando Redes de Aprendência. Web $2.0 \&$ transdisciplinaridade ${ }^{10}$. Esse foi um momento importante por aproximar os professores dos conteúdos do curso e do próprio conteúdo tecnológico, favorecendo o desenvolvimento de autonomia em mais esse ambiente virtual de aprendizagem. $\mathrm{Na}$ oportunidade a mediadora do referido fórum, foi convidada para a realização de vídeo conferência via ambiente de comunicação online Skype através do grupo "Criação e dinamização de Redes de Aprendência". A reflexão se deu sobre como elaborar e dinamizar uma rede de aprendência permeada pela transdisciplinaridade.

\footnotetext{
${ }^{6}$ Ver, por exemplo, (LÈVY, 2000, p. 17).

${ }^{7}$ Disponível em http://www.virtual.ufc.br/socrates/Default.aspx acesso 14/12/2011

${ }^{8}$ Redes de Aprendência: Reflexos e Reflexões, Disponível em https://docs.google.com/presentation/d/1qW0FniwOVhP1Z7L 8pXVAG5Kd14gxxCwP92tpydWDY/edit\#slide=id.g1f1bb0b3 $0 \_1$ acesso 10 abr 2012

${ }^{9}$ Página disponível http://www.facebook.com/cursoredes.sociais.1 acesso 27/12/2011 Acesso 27/12/11

${ }^{10}$ Disponível em http://portaldoprofessor.mec.gov.br/ListarMensagensForum.html?idTopico=122 Acesso em 10/10/2011
} 
Após a videoconferência, do dia 12/06/2012, como decorrência da discussão sobre como elaborar uma rede de aprendência, observa-se que houve um aumento significativo de participação com acessos e postagens no Fórum do Portal do Professor, bem como, durante todas as etapas do curso. O que pode ser comprovado no gráfico abaixo.
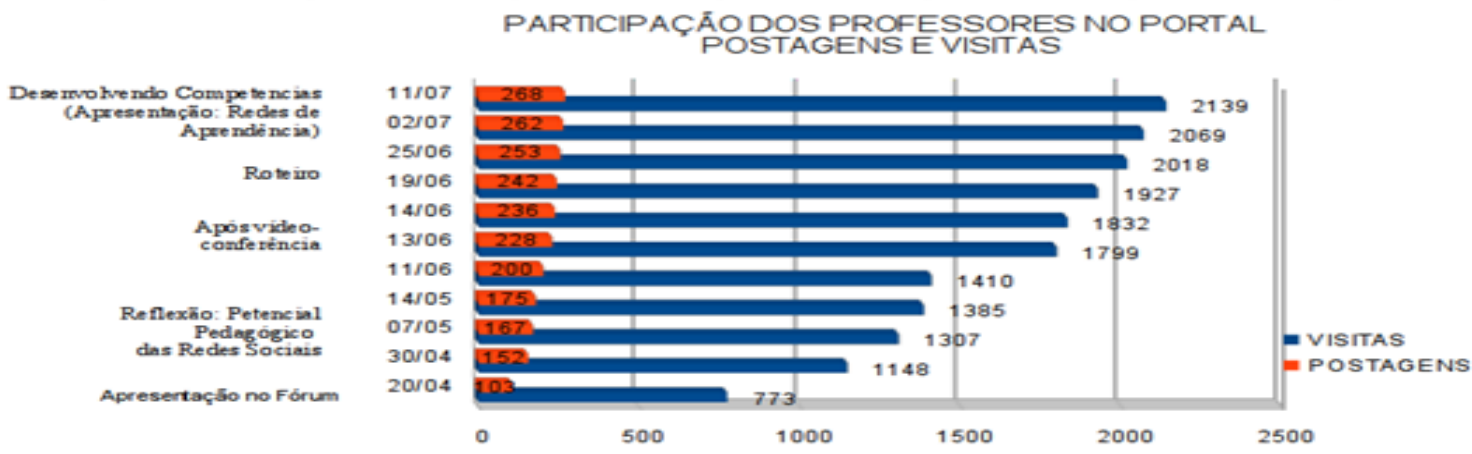

Figura 1. Observar o aumento na participação dos professores promovida pelo curso Redes Sociais: espaço de ensino e aprendizagem

Em meio a todo esse processo que se configurava como um momento de riqueza intelectual foi criado perfil na rede social Twitter ${ }^{11}$, por entender que esta ação beneficia um contexto de aprendizagem por possibilitar "Seguir" os produtos ali ligados à educação. O Twitter tornou-se um espaço de compartilhamento de material online, que pôde facilmente conectar-se a experiências de sala de aula dos professores e propiciar, a partir de recados rápidos o chamamento de questões desafiadoras, referentes a conteúdos do curso.

Finalmente como resultado de reflexões durante as aulas, um aspecto destacado pelos professores foi que atualmente o blog vem sendo utilizado com muita frequência no contexto escolar por apresentar características de incentivo à interação e à colaboração, aproximando alunos e professores. Com base nessas constatações, percebe-se que a criação de blog, inclusive como rede de aprendência, superou os outros recursos estudados visto que coloca o professor em rede, já que o mesmo expõe conteúdos de sua autoria, promove o acompanhamento das atividades e gerencia a participação dos estudantes (Cotes, 2007). Para criação do Blog "Redes de Aprendência" 12 que reúne as redes de aprendência elaboradas pelos participantes foram experimentados os recursos do Wordpress.

Uma vez que a formação apresenta-se com um diferencial no uso das ferramentas da Web 2.0, na qual o professor passa a ser produtor de conteúdos, ressaltase que na ferramenta de vídeo You Tube, os professores socializaram através de um vídeo "Redes Sociais numa perspectiva de Redes de Aprendência"13 as contribuições da formação e a constituição de suas redes de aprendências, deixando de lado a passividade colaboram e revelam suas opiniões (Oliveira, Pontes e Santana, 2011). O que pode constatar que o objetivo da formação está sendo alcançado. A primeira interação dessa maneira foi realizada pelo professor A, explicando sobre os conhecimentos construídos na formação para sua prática docente: "Ótima iniciativa! É muito bom saber que

\footnotetext{
${ }^{11}$ Perfil criado para o curso, disponível em https://twitter.com/Bessa_Curso_CRP acesso 16/04/2012.

${ }^{12}$ Ver http://redesdeaprendencia.wordpress.com/acesso em 16/07/2012

13 "Redes Sociais numa perspectiva de Redes de Aprendência" Disponível em http://www.youtube.com/watch?list=LLN3ffCQtS52TDR7zQAbp0g\&v=BjtICvBmzcQ\&feature=player embedded acesso 07/09/2012
} 
existem formas de se utilizar as redes sociais para algo construtivo e bom!" (Professor A - Comentário - Vídeo) $)^{14}$

Um dos aspectos relevantes na utilização das ferramentas da Web 2.0, em geral, diz respeito aos recursos ativos digitais disponíveis para uso de professores e alunos. Desta forma, um grupo de docentes escolheu a Plataforma Edmodo ${ }^{15}$ para a elaboração de sua rede de aprendência, por ela reunir as possibilidades de trabalhar atividades de gêneros textuais com os alunos do quinto ano.

Qualifica-se, assim, o processo de ensino e aprendizagem, nos ambientes sugeridos das redes sociais, como um meio potencial para a extensão das práticas educativas servindo tanto para os registros das percepções de mundo como para as informações que foram geradas, cocriadas ou consumidas.

\title{
5. Apresentando e discutindo os resultados
}

Aponta-se que o uso das ferramentas digitais e a criação de redes de aprendência contribuíram para o desenvolvimento das estruturas cognitivas do professor ao ampliar nele a postura investigativa e a criação de estratégias de aprendizagem, para com isso propiciar a construção de conhecimento necessária para o enfrentamento das situações desafiadoras de todo processo vivenciado no seu cotidiano pedagógico.

A proposta de uso das ferramentas digitais para criação das redes de aprendência permitiu ao professor retomar o pensamento socioconstrutivista de Vigotski (1998), ao ser criador de situações de aprendizagem e o regulador dos processos e percursos da sua formação, sentindo-se mais seguro para trabalhar com a tecnologia inserida no contexto curricular, bem como, ao observar as mudanças em sua rotina da sala de aula inovando sua prática pedagógica. As informações da Profa. B sustentam essa ideia:

\begin{abstract}
"Percebi que as minhas aulas ficaram mais interessantes. Eles se encantam com atividades propostas, e fazem brincando construindo o seu próprio conhecimento. Finalmente descobrir o que é a transdisciplinaridade. Estou trabalhando em alguns projetos na minha sala de aula e tentando contaminar os colegas que estão ao meu redor. Não tenho dúvidas em dizer que a rede de aprendência está mudando o meu ambiente de trabalho" (Profa B. Fórum Portal do Professor, 04/06/2012).
\end{abstract}

O conhecimento prévio e o novo conhecimento, caracterizando assim, aprendizagem significativa, seguida às discussões, leitura com reflexão crítica e uso das ferramentas da Web 2.0 nos contextos amplos e diversificados sugeridos pelos espaços cibernéticos, propiciaram a professora $\mathrm{C}$ ir além da sala de aula:

\footnotetext{
"Gostaria de compartilhar um pouco da minha experiência com redes sociais. No começo eu achava ruim, por não dominar a ferramenta, agora descobri várias utilidades do microblog. No meu perfil no Twitter, sigo o Maurício de Sousa e sempre levo para os meus alunos, do segundo ano do fundamental, gibis da turma da Mônica, que eles adoram. Então peguei o meu dispositivo móvel (celular) e mostrei para eles quem era que escrevia aquelas histórias que eles tanto gostavam... Interagi com ele e repassei o que ele falava para todas as crianças. Os meninos ficaram maravilhados com aquilo, o brilho no olhar era nítido, novas descobertas. Depois disso propus que eles escrevem e ilustrassem histórias, foi muito rica essa aula e inesquecível também". (Professora C, Fórum Portal do Professor, 25/04/2012).
}

\footnotetext{
${ }^{14}$ Redes de Aprendência- Comentário - Disponível em http://www.youtube.com/watchv=mjzLX1TWlao\&list=PL8039EA309981E887\&index=49\&feature=plpp video acesso jun. 2012

${ }^{15}$ Disponível em http://www.edmodo.com/profile/7696205 acesso jul 2012
} 
Já o professor $\mathrm{D}$, apresentando uma postura investigativa, diante da criação de estratégias de aprendizagem, foi levado à construção de conhecimentos necessários para o enfrentamento das situações desafiadoras ora postas. Gradativamente a cada aula observa-se o crescimento da autonomia dos participantes nos quesitos relacionamentos, criatividade e motivação para a aprendizagem. A professora D ilustra esse ponto de vista:

\begin{abstract}
"O curso terminou.... Foi esclarecedor os conteúdos e os direcionamentos recebidos durante o curso. Ou melhor, estou segura dos objetivos e como eu vou usar as redes sociais na educação nas Séries Iniciais. Pesquisei e encontrei nas redes sociais o que buscava uma maneira de atrair meus alunos de mantê-los concentrados em algo". (Professora D, Fórum Portal do Professor, 02/06/2012).
\end{abstract}

O professor E demonstra ter ampliado sua capacidade para uso das ferramentas Web 2.0 nos aspectos comunicativos de coautoria ao sentir-se estimulado para a própria aprendizagem e apropriação dos conteúdos da cibercultura:

\footnotetext{
"Vim para o curso de redes sociais porque percebo que meus alunos acessam e não tiram um proveito melhor para o lado da educação. E queria fazer algo, mostrar que não é só fofoca, curtir e compartilhar. Eles podem adquirir conhecimentos nas redes sociais para um melhor aproveitamento na escola". (Professor. E. Fórum de Apresentação - Sócrates, 21/5/2012).
}

Quanto mais o professor se tornava aprendente mais se mostrava em condição de dinamizar sua rede e divulgar suas experiências de sucesso no processo de ensinoaprendizagem. Nesse sentido, foi essencial ao processo de desenvolvimento do curso a incorporação das ferramentas digitais para elaboração das redes de aprendência, configurando-se como inovação educacional.

\title{
6. Considerações Finais
}

A riqueza desse estudo se deu pelo fato dos docentes permitirem e apresentarem novos modos de saber fazer configurando abertura em sua práxis. Em seguida quando da elaboração e dinamização das redes de aprendência, vislumbravam uma dinâmica de motivação diferente e uma abordagem diferenciada para seus alunos, tendo a oportunidade de melhorar a qualidade de suas aulas com atividades integradas aos recursos digitais em sintonia com a atualidade.

Os resultados foram identificados recorrendo-se aos registros de criação, colaboração e compartilhamento dos serviços utilizados após a dinamização das redes de aprendência, no âmbito de atuação de cada um dos participantes. As ferramentas digitais trabalhadas ofereceram aos professores a ampliação da capacidade para inserir a tecnologia na prática pedagógica; verificamos novas formas de relacionamento entre os alunos e uma maior integração entre os conteúdos propostos e o cotidiano vivenciado pelos eles nas redes sociais.

De toda a análise conclui-se que a principal contribuição do curso para o educador, após a apropriação, integração e uso das ferramentas digitais de forma pedagógica, foi a percepção de novas formas de ensinar e aprender através das redes de aprendência, assim como o favorecimento de mudança em sua ação e postura docente.

Constata-se pelos resultados que, nessa perspectiva de criação, colaboração e compartilhamento, os professores-cursistas aprenderam fazendo, criando e dinamizando redes de aprendência, com alternância nos papéis de "aprendente" e de "educante" 
inovando a produção do saber e repensando práticas pedagógicas à proporção que avançavam na apropriação e no uso dessas ferramentas digitais.

\section{7- Referências}

Almeida M. E.B: Prática e Formação de Professores na Integração de Mídias, Série "Pedagogia de Projetos e Integração de Mídias" Integração das tecnologias na Educação Ministério da Educação, Seed, 2005. 204 p.; Il.

.M. E. B; Moran, J. M. (Org.) Integração das tecnologias na educação. Brasil: Ministério da Educação, Seed, 2005. Disponível em http://www.tvebrasil.com.br/salto/livro.htm Acesso em: 20/ jan./2010.

Balbino, F. C. e Anacleto, J. C. Redes Sociais Online Orientadas à Difusão de Inovações como Suporte à Extensão de Práticas Educativas. Anais do XXII SBIE XVII WIE Aracaju, 2011.

Barcelo, G. T.; Passerino, L. M.; Behar, P. Formação continuada de professores: rede social na Interent apoiando uma comunidade prática. Anais do XXII SBIE - XVII WIE Aracaju, 21- 25 de novembro de 2011.

Buzato,M.E.K. Letramentos Digitais e Formação de Professores. III Congresso Ibero Americano Educarede, $2006 . \quad$ Disponível http://www.educared.org/educa/img_conteudo/marcelobuzato.pdf

Cotes, P. Quer Aprender? Crie um blog. São Paulo: Revista Época, Ed. 456, 12 fev. 2007. Disponível em http://revistaepoca.globo.com/Revista/Epoca/0,EDG76347-6014456,00.html Acesso em: 26/ jan./2011.

Fabre, H.T. A Árvore do Saber-Aprender, São Paulo: Editora Triom, 2004. Fichmann, S. A Gestão Transdisciplinar de uma Comunidade Virtual de Aprendizagem: Projeto Telemar Educação. Dissertação de Mestrado. Ciências da Comunicação. Escola de Comunicação e artes (ECA-USP). (2005, p. 61). Disponível em http://www.abed.org.br/ciclodecursos/SilviaFichmann.pdf acesso em abril 2012

S. Formação de formadores, transdisciplinaridade e tecnologia: uma utopia?In: Friaça, A. Alonso, L. K; Lacombre, M.; Barros, V. M. Educação e Transdisciplinaridade III. São Paulo: Triom, 2005. p.12

Kensky,V.M. Tecnologias digitais na Educação- Salto para o futuro-2009- Disponível em http://www.youtube.com/watch?v=wZ3k4IocB6M Acesso em fev./2012

Levy, P. Cibercultura. Tradução de Carlos Irineu da Costa. S. P: Editora34, 2000 p.17. Oliveira. F.K, Pontes. M.G.O. Santana. J.R. O vídeo pela Internet como ferramenta educacional. Inovações, Cibercultura e Educação. Fort; Ed. UFC, 2011. pág. 110-112.

Perrenoud, P. Dez Novas Competências para Ensinar. P Alegre: Artes Médicas, 2000. Pontes, R. L. J. e Castro-Filho. J. A. O uso do blog como ferramenta de ensinoaprendizagem por professores participantes do Projeto Um Computador por Aluno (UCA). Anais do XXII SBIE - XVII WIE Aracaju, 21- 25 de novembro de 2011 Recuero, R. C. Redes sociais na internet: Considerações iniciais. IV Encontro Dos Núcleos de Pesquisa da XXVII INTERCOM, Porto Alegre/RS, 2004.

Silva. S. Redes sociais Digitais e Educação. Revista Iluminart, IFSP - Campus do

Sertãozinho, São Paulo n 5: p.40, ago.2010.

Tori, R. Educação sem distância: as tecnologias na redução de distancias em ensino e aprendizagem. Editora Senac, São Paulo, 2010. p. 217, 219.

Vygostsky, L.S A formação social da mente: o desenvolvimento dos processos psipocólogicos superiores. 7. ed. São Paulo: Martins Fontes, 1998.

Wesch, M. Web 2.0: A Máquina Somos Nós. Vídeo. Disponível em: http://www.youtube.com/watch?v=NJsacDCsiPg . Acesso em: jun./2011 